\title{
EDEMA AND MALIGNANCY IN MENINGIOMAS
}

Tobias Alécio Mattei, Josias Alécio Mattei, Ricardo Ramina, Paulo Henrique Aguiar, José Pindaro Plese, and Raul Marino Jr.

Mattei TA, Mattei JA, Ramina R, Aguiar PH, Plese JP, Marino Jr. R. Edema and malignancy in meningiomas. Clinics. 2005;60(3):201-6.

PURPOSE: In recent years there have been many attempts to define a subset of aggressive malignant meningiomas based on histopathology and imaging technologies. The purpose of this study was to evaluate the level of peritumoral edema and its volume using the imaging technologies, computer tomography and magnetic resonance imaging, and correlate these results with the histological WHO classification. Reported causes of tumoral edema and its relationships to the histological characteristics were also reviewed.

METHODS: The cases of 55 patients with meningiomas who underwent surgery at the Hospital das Clinicas (Fac Med Univ Sao Paulo) between September 1993 and September 1997 were reviewed. The level of edema according to the classification of Ide et al. (1995) was compared to the histological WHO classification.

RESULTS: Classification of the degree of edema was: level 0 edema - 28 cases ; level I edema - 19 cases; level II edema 8 cases. Histological classification was: benign meningioma - 43 cases; atypical meningiomas - 11 cases; malignant meningioma -1 case. There was a significant $(P=.0089)$ correlation between the degree of tumoral edema and the histological characteristics.

CONCLUSIONS: These results suggest that the degree of edema as revealed by computer tomography and magnetic resonance imaging can be an important clinical predictive factor for the histological grade of the meningioma.

KEYWORDS: Edema. Meningioma. Malignant meningiomas.Magnetic resonance imaging. Computed tomographic scan.

Tumors derived from meningothelial cells are among the most frequent neoplasms of central nervous system. Fortunately, the majority of cases have a benign clinical course, and some are asymptomatic. Meningiomas are generally well circumscribed, slow- growing lesions that are amenable to total surgical resection; they account for $13 \%$ to $19 \%$ of all brain tumors treated by surgery. ${ }^{2,3}$ Intracranial meningiomas are found approximately twice as often in women as in men. Their size may increase during pregnancy, and they have been described to be occasionally associated with breast cancer. $^{4}$

Department of Neurosurgery, Hospital das Clínicas, Faculty of Medicine, University of São Paulo - São Paulo/SP, Brazil.

E-mail: tobiasmattei@hotmail.com

Received for publication on September 01, 2004

Accepted for publication on January 07, 2005.
Aggressive behavior has been described in these tumors; more recently, there have been attempts to define a subset of malignant meningiomas using histopathology. One of the major problems is the discrepancy between histological morphology and tumor behavior.

The proliferative potential of meningiomas is variable; some of them remain unchanged in size for long periods of time, whereas others grow rather quickly.

The purpose of the study was to assess, using computer tomography (CT) and magnetic resonance imaging (MRI), the level and volume of peritumoral edema, and to correlate these with the histological WHO classification.

\section{PATIENTS AND METHODS}

Intracranial meningiomas that were surgically resected from 55 patients (September 1993 to September 1997) were 
included in this study. All patients had both preoperative computed tomography (CT) and magnetic resonance imaging (MRI) available. Clinical, surgical, pathological, and neuroimaging reports were reviewed in all cases.

Thirty-eighty patients were women and 17 were men, with ages ranging from 9 to 82 years $($ mean $=49.87 \pm 16.80)$. For histological examination, samples were fixed in formalin and embedded in paraffin. Slides were stained with hematoxylin and eosin, and Masson's trichrome when indicated. Meningiomas were classified according to the WHO classification ${ }^{5,6}$ into benign, atypical, and malignant groups. Brain invasion is required for the diagnosis of malignant meningiomas; therefore, if no cortical tissue was present in the examined sections, a diagnosis of malignant meningioma could not be made. In this series, there were 43 benign tumors, 11 atypical tumors, and 1 malignant tumor.

\section{Peritumoral edema in preoperative CT and MR images}

Location and size of the tumor as well as extent of the peritumoral edema were determined by preoperative CT and MRI. Regarding the location of the tumors, 20 were in the convexity of the brain, 28 in the parasagittal region and falx, 2 in the sphenoid ridge and cavernous sinus, 3 in the olfactory groove, 1 in the foramen magnum, and 1 adhered to the tentorium. Regarding attachment to the skull base, 49 tumors were supratentorial with no attachment to skull base (group A) and 6 (group B) were attached to the skull base in either the middle or posterior fossa.

The extent of peritumoral edema was determined using brain CT and MRI. Edema was identified either as a hypodense area around the tumor on brain CT images or as a hyperintense signal on a T2-weighted MRI image; the extent of peritumoral edema was graded-0 (GR0), 1 (GR1), or 2 (GR 2), ${ }^{17,}{ }^{30}$ where GR0 represents either absence of edema or the presence of a small halo around the tumor; GR1 represents edema extending variably along the tracts of the white matter but without involvement of the whole hemisphere; and GR2 represents holohemispheric or near holohemispheric edema.

\section{Statistical method}

Data were entered into a database on a personal computer and analyzed using the statistical software, Statmost. Statistical analysis was performed using the chi-square test to determine the correlation of histological features with the edema level. Statistical significance was declared when $P<.05$.

\section{RESULTS}

Classification of the extent of peritumoral edema was GR0: 28 cases; GR1: 19 cases; GR2: 8 cases.

There was a statistically significant correlation between the histological features and the extent of peritumoral brain edema $(P=.0089)$. In GR0, we found 23 tumors of the benign (B) histological subtype and 5 tumors of the atypical/ malignant $(\mathrm{A} / \mathrm{M})$ meningioma subtype; in GR1 there were 17 tumors of the B histological subtype and 2 tumors of the $\mathrm{A} / \mathrm{M}$ meningioma subtype; and in GR3 there were 3 tumors of the B histological subtype and 5 tumors of the $\mathrm{A} / \mathrm{M}$ meningioma subtype (Table 1 ). The

statistically significant correlation occurred only when the tumors were divided into 2 groups according to the histological subtypes, 1) atypical, malignant meningiomas (A/ $\mathrm{M})$ and 2) benign meningiomas (B).

\section{DISCUSSION}

Peritumoral edema is a special problem with meningiomas, with an incidence of about $40 \%$ to $78 \%,{ }^{10-12}$ that makes the surgical management of the meningiomas difficult. Significant brain edema may cause severe neurologic deficits and limit the surgical field during the approach. However, in our experience and in that of Ohno et al., ${ }^{9}$ the presence of arachnoid in the tumor bed at areas of softened and edematous brain tissue is seldom observed in spite of careful removal of the tumors.

The probable etiologies of peritumoral edema include tumor size, histologic subtypes, vascularity, venous stasis, type of arterial supply, sex hormone receptors, secretory activity, inflammation (lymphocytes and macrophage infiltrates ), or brain invasion. ${ }^{13-26}$

Macrophage infiltration was found to be correlated with peritumoral edema in 12 of 16 meningiomas studied. ${ }^{27}$ Macrophages are known to secrete various substances (including arachidonic acid metabolites) that may interfere with vascular permeability.

A consistent correlation between the presence of edema and the type of vascular supply to the tumor has been demonstrated. ${ }^{12}$ When there is no edema, the entire vascular supply of the tumor is provided by the meningeal branches of external or internal carotid arteries. When there is peritumoral edema, the vascular supply of the portion of the tumor adjacent to the edema is provided by leptomeningeal branches of the internal carotid. ${ }^{28}$ The importance of pial blood supply in the development of peritumoral edema in meningiomas is well known. This supply may be detected by means of angiography and compared with the edema ratio using computerized tomography. ${ }^{29}$ 
The histopathological features of tumor aggressiveness (Figure 1), or mechanical parameters such as volume, location, and insertion site, have not correlated well with edema parameters or with prostaglandin levels. ${ }^{30-34}$

Two distinct patterns of edema can be distinguished. One pattern is that of a diffuse white-matter process appearing to represent active transudation of water into white matter, which occurs in $43 \%$ of tumors with edema. The second pattern, occurring in $57 \%$ of tumors with edema, is a localized peritumoral process. This distinction has important pathophysiologic and clinical implications. In one study, ${ }^{35}$ the diffuse pattern did not appear to reflect tumor size: it was found in $54.6 \%$ of tumors from 2 to $4 \mathrm{~cm}$ in diameter and in $33 \%$ of tumors over $4 \mathrm{~cm}$. It appeared more often in tumors of the lateral sphenoid wing or subfrontal region, and it was more often associated with the atypical and syncytial histological subtypes and appeared to reflect some intrinsic property of the tumor rather than compression of surrounding structures. The various histological subtypes

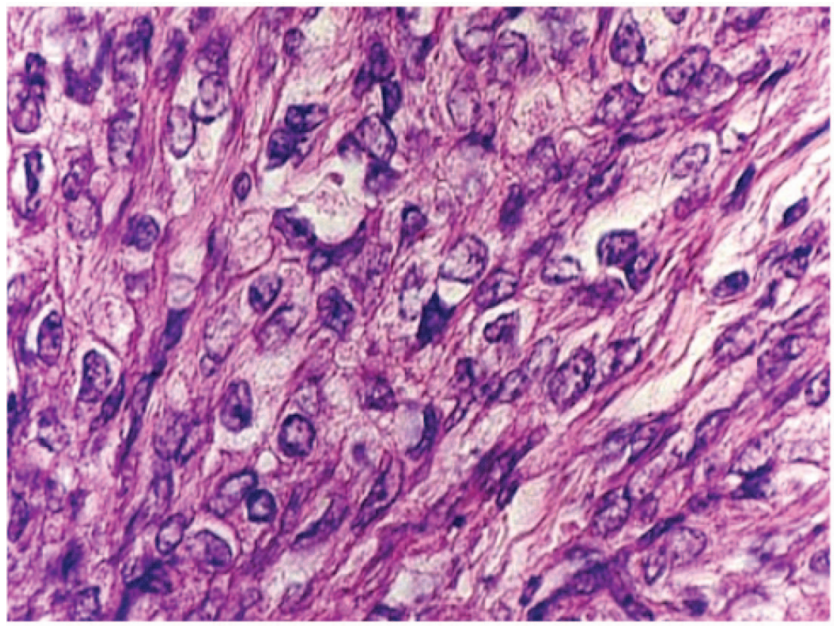

Figure 1 - Histopathological features of a malignant meningioma: mitotic cells, areas of micro-necrosis, multinuclear cells, abnormal nuclear form, prominent nucleolus.

Table 1 - Type of meningioma versus peritumoral edema using Magnetic resonance imaging and brain computer tomography. There was a statistically significant correlation between the histological features and extent of peritumoral brain edema $(P=.0089$, chi-square test $)$.

\begin{tabular}{lcccc}
\hline & GRO & GR1 & GR2 & Total \\
\hline Benign & 23 & 17 & 3 & 43 \\
Atypical/Malignant & 5 & 2 & 5 & 12 \\
Total & 28 & 19 & 8 & 55
\end{tabular}

GR0 = either absence of edema or the presence of a small halo around the tumor; GR1 = edema extending variably along the tracts of the white matter but without involvement of the whole hemisphere; GR2 $=$ holohemispheric or near holohemispheric edema also seem to be distinct in their tendency to induce edema, with transitional and meningotheliomatous subtypes being associated with the more severe grades of edema. ${ }^{35,36}$ In the present study, no statistical correlation was found between the histological grade of malignancy and histological

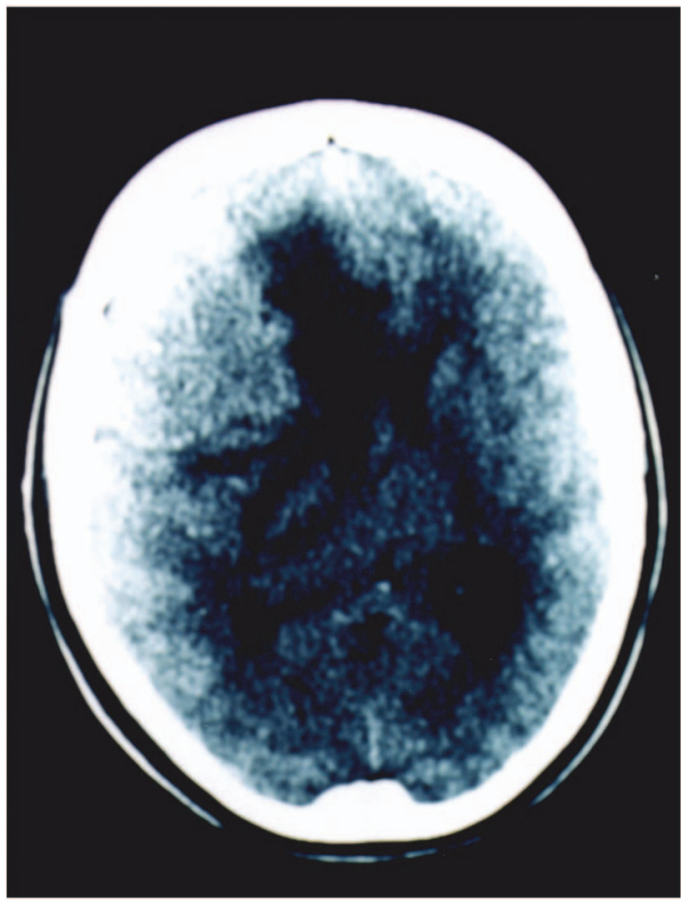

Figure 2 - Computer tomography image showing large malignant meningioma with intense peritumoral edema.

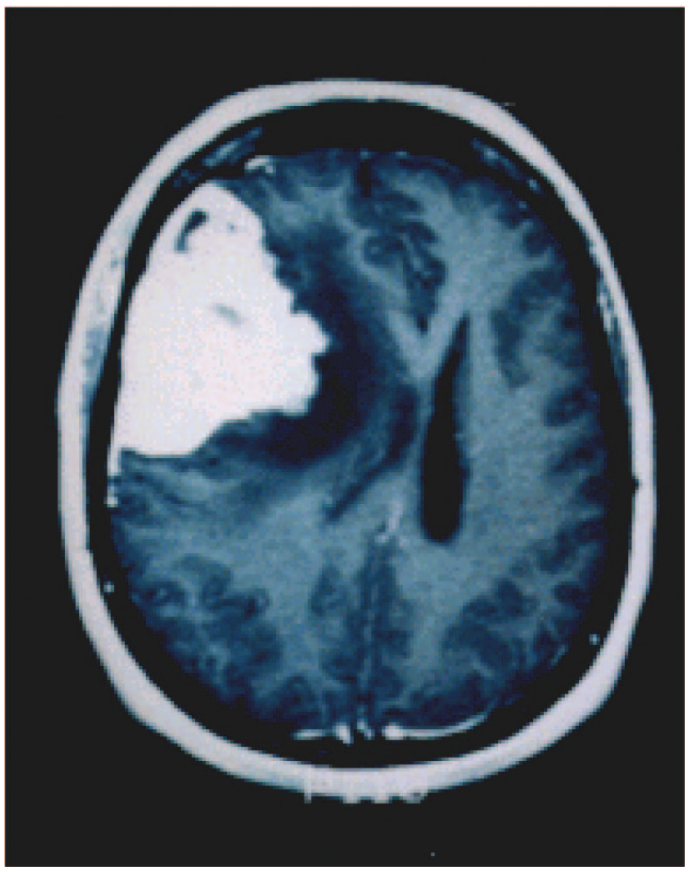

Figure 3 - Mmagnetic resonance imaging showing large malignant meningioma with important peritumoral edema and deviation of the middle line structures. 
subtypes, probably due to the large distribution of the several subtypes and the small group analyzed (Table 1).

In another study, the degree of peritumoral brain edema as identified by CT was found to correlate with the clinical evolution and the size of the tumors, whereas correlation with the histological features are less significant. ${ }^{37}$

Several studies have indicated that the hypodense area surrounding meningiomas does not solely represent vasogenic edema but may represent tumor pressure ischemia. ${ }^{30,38,39}$ In one study, in individual cases, blood flow values in the peritumoral edematous area were very low. ${ }^{13,38}$

Regarding the correlation between histological features and degree of malignancy of meningiomas, we found a statistically significant correlation between the histological grade and the edema level. Correlation of mitosis and necrosis with brain edema in was found in $92 \%$ of the cases in one previous study, ${ }^{37}$ but this correlation was not seen in other series. ${ }^{40,41,42}$

Regarding the correlation of results of CT with the malignancy of the meningiomas, one study showed that 3 kinds of tumor-brain interfaces characterized by different difficulties in microsurgical dissection-smooth type, tran- sitional type, and invasive type-were very precisely correlated with CT images of halo-like and finger-like hypodense areas, allowing prediction of the microsurgical effort to be made in surgery for removal of meningiomas.

Possible mechanisms of formation of the peritumoral edema have been postulated. Ide et al. ${ }^{25}$ observed that brain edema correlated significantly with evidence of leptomeningeal and cortical damage from the tumor suggesting that larger tumors could destroy the leptomeninges and cerebral cortex, allowing direct transmission of edema fluid into the white matter and resulting in vasogenic edema.

A current theory is based on the _expression of vascular permeability factor/vascular endothelial growth factor (VPF/VEGF) when a cerebral-pial supply or neovascularization exists ${ }^{44-46}$ and on the presence of platelet-activating factor, which may arise from infiltrating leukocytes. ${ }^{47}$ Growth potential, as determined by the presence of the Ki-67 antigen determined by immunostaining with MIB-1 monoclonal antibody,

increases with increasing severity of peritumoral brain edema, indicating a close relationship between tumor aggressiveness and edema development. ${ }^{48,49}$

\section{RESUMO}

Mattei TA, Mattei JA, Ramina R, Aguiar PH, Plese JP, Marino Jr. R. Edema e malignidade em meningiomas. Clinics. 2005;60(3):201-6.

OBJETIVO: Nos últimos anos têm-se descrito alguns subtipos de meningiomas de comportamento peculiarmente agressivo. Muitas tentativas têm sido feitas no intuito de estabelecer critérios imagenológicos ou histopatológicos de malignidade. O objetivo desse estudo é avaliar, através de Tomografia Computadorizada e Ressonância Nuclear Magnética o grau de edema peritumoral e seu volume, correlacionando-os com a classificação histológica da OMS. As causas relatadas de edema peritumoral e sua possível correlação histológica foram também revistos.

MÉTODOS: Foram estudados 55 casos de meningiomas operados no Hospital das Clinicas (FMUSP) entre Setembro de 1993 e Setembro de 1997. O grau de edema segundo a classificação de Ide et al. (1995) foi comparado com a classificação da OMS.

RESULTADOS: Os achados relativos a edema foram: edema grau 0 - 28 pacientes; grau I - 19 pacientes; grau II - 8 pacientes. A classificação histológica demonstrou: meningiomas benignos - 43 casos; meningiomas atípicos - 11 casos meningioma maligno - 1 caso. Demonstrou-se uma correlação significativa ( $\mathrm{p}=0,0089$ ) entre o grau de edema dos meningiomas e suas características histológicas.

CONCLUSÕES: Esses resultados sugerem que o grau de edema avaliado imagenologicamente pela Tomografia Computadorizada e Ressonância Nuclear Magnética pode ser um importante fator preditivo da gradação histológica dos meningiomas.

UNITERMOS: Edema. Meningioma. Meningiomas malignos. Ressonância nuclear magnética. Tomografia computadorizada. 


\section{REFERENCES}

1. Ide M, Jimbo M, Kubo O, Yamamoto M, Takeyama E, Imanaga $\mathrm{H}$. Peritumoral brain edema and cortical damage by meningioma. Acta Neurochir. 1994;60:369 -72.

2. Black PM. Meningiomas. Neurosurgery. 1993;32: 643-57.

3. Russel D S, Rubinstein LJ. Tumors and tumor like lesions of maldevelopmental origin. In: Pathology of tumors of the nervous system. Russel DS, Rubinstein LJ, (editors) Williams\& Wilkins, Baltimore, 1989, p 452-53.

4. Bouillot P, Pellissier JP, Devictor B, Graziani N, Bianco N, Grisoli F. Quantitative imaging of estrogen and progesterone receptors, estrogen-regulated protein, and growth fraction: immunocytochemical assays in 52 meningiomas. Correlation with clinical and morphological data. J Neurosurg. 1994;81:765-73.

5. Kleihues P, Burger PC, Scheithauer BW. Histological typing of tumours of the central nervous system. In: WHO (editors). International histological classification of tumours. Springer, Berlin 1993; pp. 33-42.

6. Maier H, Öfner D, Hittmair A, Kitz K, Budka H. Classic, atypical, and anaplastic meningioma: three histopathological subtypes of clinical relevance. J Neurosurg. 1992;77: 616-23.

7. Gerdes J, Schwab U, Lemke H, Stein H. Production of a mouse monoclonal antibody reactive with a human nuclear antigen associated with cell proliferation. Int J Cancer. 1983;31:13-20.

8. Langford LA, Cooksley CS, De Monte F. Comparison of MIB-1 (Ki -67) antigen and bromodeoxyuridine proliferation indices in meningiomas. Hum Pathol. 1996;27:350-4.

9. Ohno K, Matsushima Y, Aoyagi M, Ikeda J, Suzuki R, Ichimura K et al. Peritumoral cerebral edema in meningiomas: the role of role of the tumor -brain interface. Clin Neurol Neurosurgery. 1992;94: 291-5.

10. Gilbert JJ, Paulseth JE, Coates RK, Mallot D. Cerebral edema associated with meningiomas. Neurosurgery. 1983;12:599-605.

11. Smith H P, Challa V R, Moody D M, Kelly D L Jr. Biological features of meningiomas that determine the production of cerebral edema. Neurosurgery. 1981;8:428-33.

12. Stevens JM, Ruiz JS, Kendall BE. Observation on peritumoural oedema in meningioma. Part I: distribution, spread and resolution of vasogenic oedema seen on computed tomography. Neuroradiology. 1983;25:71-80.

13. Benzel EC, Gelder FB. Correlation between sex hormone binding and peritumoral edema in intracranial meningiomas. Neurosurgery. 1988;23:169-74.

14. Bradac GB, Ferzt R, Bender A, Schoener W. Peritumoral edema in meningiomas: a radiological and histological study. Neuroradiology. 1986;28:304-12.

15. Brandis A, Mirzai S, Tatagiba M, Walter GF, Samii M, Ostertag H. Immunohistochemical detection of female sex hormone receptors in meningiomas: correlation with clinical and histological features. Neurosurgery. 1993;33:212-8.

16. Challa VR, Moody DM, Marshall RB, Kelly DL Jr. The vascular component in meningiomas associated with severe cerebral edema. Neurosurgery. 1980;7:363-8.
17. Dieteman JL, Heldt N, Burguet JL, Medjek L, Maitrot D, Wackenheim A. CT findings in malignant meningiomas. Neuroradiology. 1982;23:207-9.

18. Go K G, Wilmink JT, Molenaar WM. Peritumoral brain edema associated with meningiomas. Neurosurgery. 1988; 3:175-9.

19. Ide M, Jimbo M, Yamamoto M, Umebara Y, Hagiwara S, Kubo O. MIB-1 staining index and peritumoral brain edema of meningiomas. Cancer. 1995;78:133-43.

20. Inamura T, Nishio S, Takeshita I, Fujisawa S, Fukui M. Peritumoral brain edema in meningiomas: influence of vascular supply on its development. Neurosurgery. 1992;31: 179-85.

21. Maiuri F, Gangemi M, Cirillo S, Delehaye L, Gallicchio B, Carandente $\mathrm{M}$ et al. Cerebral edema associated with meningiomas. Surg Neuro. 1987; 27:64-8.

22. Maiuri F, Montagnini S, Iaconetta G, Gallicchio B, Bernardo A, Signorelli F. Correlation between sex hormone receptors and peritumoral edema in intracranial meningiomas. J Neurosurg Sci. 1994;38: 29-33

23. Salpietro FM, Alafaci C, Lucerna S, Iacopino DG, Todaro C, Tomasello F. Peritumoral edema in meningiomas: microsurgical observation of different brain tumor interfaces related to computed tomography. Neurosurgery. 1994;35:638-42.

24. Sato K, Kuratsu J, Takeshima H, Yoshimura T, Ushio Y. _Expression of monocyte chemoattractant protein- 1 in meningioma. J Neurosurg. 1995;82:874-8

25. Shinonaga M, Chang CC, Suzuki N, Kuratsu J, Kendall BE, Yoshimura T. Immunohistological evaluation of macrophage infiltrates in brain tumors. Correlation with peritumoral edema. J Neurosurg. 1988;68:259-65.

26. Casasco A, Mani J, Alachkar F, Moody DM, Marshall RB, Kelly DL Peritumoral edema in intracranial meningiomas. Angiographic and computerized tomographic correlations. Neurochirurgie. 1986; 32:296-303

27. Bitzer M, Wockel L, Luft AR, Bharara S, Palmer CA Hama S. The importance of pial blood supply to the development of peritumoral brain edema in meningiomas. J Neurosurg. 1997;87:368-73.

28. Constantini S, Tamir J, Gomori MJ, Burger PC, Scheithauer BW, Cooksley CS. Tumor prostaglandin levels correlate with edema around supratentorial meningiomas. Neurosurgery. 1993;33:20410 .

29. Hwang S1, Howng SL. Peritumoral brain edema in intracranial meningiomas. Gaoxiong Yi Xue Ke Xue Za Zhi. 1990;6:614-20.

30. Ide M, Jimbo M, Yamamoto M, Umebara Y, Hagiwara S, Kubo O. Peritumoral brain edema associated with meningioma-histological study of the tumor margin and surrounding brain. Neurol Med Chir. 1992; 32:65-71.

31. Abe T, Black Pm, Ojemann RG, Hedley-White ET. Cerebral edema in intracranial meningiomas: evidence for local and diffuse patterns and factors associated with its occurrence. Surg Neurol. 1994; $42: 471-5$

32. Philippon J, Guyot JF. Current data on cerebral edema. II Therapeutical aspects. Presse Med. 1968;76:2393-4. 
33. Tatagiba M, Mirzai S, Samii M. Peritumoral blood flow in intracranial meningiomas. Neurosurgery. 1991;28:400-4.

34. Cho KG, Hoshino T, Nagashima T, Murovic JA, Wilson CB. Prediction of tumor doubling time in recurrent meningiomas. $\mathrm{J}$ Neurosurg. 1986;65:790-4.

35. Goldman Ck, Bharara S, Palmer CA. Brain edema in meningiomas is associated with increased vascular endothelial growth factor expression. Neurosurgery. 1997;40:1269-77.

36. Provias J, Claffey K, Delaguila L. Meningiomas: role of vascular endothelial growth factor/vascular permeability factor in angiogenesis and peritumoral edema. Neurosurgery. 1997;40:1016-26.

37. Yoshioka H, Hama S, Taniguchi E. Peritumoral brain edema associated with meningioma: influence of vascular endothelial growth factor_expression and vascular blood supply. Cancer. 1999; 15:936-44.

38. Hirashima Y, Hayashi N, Fukuda O. Platelet-activating factor and edema surrounding meningiomas. J Neurosurg. 1998;88:304-7.

39. Aguiar PH, Tsanaclis AM, Tella OI Jr. Proliferation rate of intracranial meningiomas as defined by the monoclonal antibody MIB-1: correlation with peritumoural oedema and other clinicoradiological and histological characteristics. Neurosurg Rev. 2003;26:221-8.

40. Ahyai A, Spaar FW. DNA and prognosis of meningiomas: a comparative cytological and fluorescence-cytophotometrical study of 71 tumors. Acta Neurochir. 1987;87: 119-28.

41. Assieti R, Butti G, Magrassi L, Danova M, Riccardi A, Gaetani P. Cell-kinetic characteristics of human brain tumors. Oncology. 1989;47:344-51.
42. New PF, Hesselink JR, O'Carroll CP, Kleinman GM. Malignant meningiomas: $\mathrm{CT}$ and histologic criteria, including a new $\mathrm{CT}$ sign. AJNR Am J Neuroradiol. 1982; 3:267-76.

43. Kallio M, Sankila R, Hakulinen T. Factors affecting operative and excess long-term mortality in 935 patients with intracranial meningioma. Neurosurgery. 1992;31:2-12

44. Maier H, Morimura T, Öfner D, Hallbrucker C, Kitz K, Budka H. Argyrophilic nucleolar organizer region proteins (Ag NORs ) in human brain tumors: relations with grade of malignancy and prolifeation indices. Acta Neuropathol. 1990;80:156-62.

45. Nakabayashi H, Sakaguchi M, Katsuyama J, Hakuba A. Proliferative potential of meningiomas evaluated by proliferating cell nuclear antigen expression. J Neurooncol. 1995;24: 209-17.

46. Ohta M, Iwaki T, Kitamoto T, Takeshita I, Tateishi J, Fukui M MIB1 staining index and scoring of histologic features in meningioma: indicators for the prediction of biologic potential and postoperative management. Cancer. 1994;74:3176-89.

47. Philippon J, Foncin JF, Grob R, Srour A, Poisson M, Pertuiset BF. Cerebral edema associated with meningiomas: possible role of a secretory-excretory phenomenon. Neurosurgery. 1984;14: 295-01.

48. Hara A, Hirayama H, Sakai N, Yamada H, Tanaka T, Mori H. Nucleolar organizer region score and Ki-67 labelling index in high-grade gliomas and metastatic brain tumors. Acta Neurochir. 1991;109:37-41.

49. Shibuya M, Satoyuki I, Miwa T, Davis RL, Wilson CB, Hoshino T. Proliferative potential of brain tumors. Analyses with Ki-67 and anti-DNA polymerase alpha monoclonal antibodies, bromodeoxyuridine labeling, and nucleolar organizer region counts. Cancer. 1993; 71:199-206. 